\title{
Past and current perspective on new therapeutic targets for Type-II diabetes
}

\author{
This article was published in the following Dove Press journal: \\ Drug Design, Development and Therapy \\ 22 May 2017 \\ Number of times this article has been viewed
}

\section{Pradip D Patill,* \\ Umesh B Mahajan ${ }^{1, *}$ \\ Kalpesh R Patil ${ }^{2, *}$ \\ Sandip Chaudhari' \\ Chandragouda R Patil' \\ Yogeeta O Agrawal ${ }^{3}$ \\ Shreesh Ojha ${ }^{4}$ \\ Sameer N Goyal' \\ 'Department of Pharmacology,}

R. C. Patel Institute of Pharmaceutical

Education and Research, ${ }^{2}$ Department of Pharmacology, H. R. Patel Institute of Pharmaceutical Education and Research, ${ }^{3}$ Department of

Pharmaceutics and Quality Assurance, R. C. Patel Institute of Pharmaceutical Education and Research, Shirpur,

Dhule, Maharashtra, India;

${ }^{4}$ Department of Pharmacology and

Therapeutics, College of Medicine and Health Sciences, United Arab Emirates University, Abu Dhabi, UAE

*These authors contributed equally to this work

Correspondence: Sameer N Goyal Department of Pharmacology, R. C. Patel Institute of Pharmaceutical Education and Research, Karwand Naka, Shirpur, Dhule, Maharashtra, India 425405

$\mathrm{Tel}+9102563255189$

Fax +9l 02563251808

Email goyal.aiims@gmail.com

Shreesh Ojha

Department of Pharmacology and

Therapeutics, College of Medicine and Health Sciences, United Arab Emirates, University, PO Box I7666, Al Ain,

Abu Dhabi, UAE

Tel +97| 3 I 37524

Fax +97I 37672033

Emailshreeshojha@uaeu.ac.ae
Abstract: Loss of pancreatic $\beta$-cell function is a hallmark of Type-II diabetes mellitus (DM). It is a chronic metabolic disorder that results from defects in both insulin secretion and insulin action. Recently, United Kingdom Prospective Diabetes Study reported that Type-II DM is a progressive disorder. Although, DM can be treated initially by monotherapy with oral agent; eventually, it may require multiple drugs. Additionally, insulin therapy is needed in many patients to achieve glycemic control. Pharmacological approaches are unsatisfactory in improving the consequences of insulin resistance. Single therapeutic approach in the treatment of Type-II DM is unsuccessful and usually a combination therapy is adopted. Increased understanding of biochemical, cellular and pathological alterations in Type-II DM has provided new insight in the management of Type-II DM. Knowledge of underlying mechanisms of Type-II DM development is essential for the exploration of novel therapeutic targets. Present review provides an insight into therapeutic targets of Type-II DM and their role in the development of insulin resistance. An overview of important signaling pathways and mechanisms in Type-II DM is provided for the better understanding of disease pathology. This review includes case studies of drugs that are withdrawn from the market. The experience gathered from previous studies and knowledge of Type-II DM pathways can guide the anti-diabetic drug development toward the discovery of clinically viable drugs that are useful in Type-II DM.

Keywords: Type-II diabetes mellitus, therapeutic targets, discontinued drugs, insulin resistance

\section{Introduction}

Diabetes mellitus (DM) is the oldest disease known to mankind since about 3,000 years ago and is referred to in ancient Egyptian treatise. ${ }^{1}$ The prevalence of $\mathrm{DM}$ is continuously increasing and recent estimate shows that DM incidence will rise from 366.2 million people to 551.8 million by $2030 .^{2,3}$ Generally, DM is classified as either Type-I or II, but Type-II DM is more prevalent form of diabetes. The long-term macrovascular and microvascular complications associated with Type-II DM typically ends up in morbidity and mortality. Type-II DM has a complex and multifactorial pathogenesis. It occurs either due to impaired insulin secretion by pancreas or development of insulin resistance at target tissues. Insulin maintains the energy homeostasis by increasing glucose uptake into peripheral tissues and decreasing release of stored lipids from adipose tissue. ${ }^{4}$ Dysfunction of $\beta$-cell decreases insulin secretion and alters the glucose homeostasis. ${ }^{5}$ Multiple biochemical pathways show the correlation between hyperglycemia and vascular complications. Type-II DM has a role in the development of cardiovascular and kidney diseases. ${ }^{6-8}$ Type-II DM is manifested by increased glucose production, defective insulin secretion and abnormal insulin action. ${ }^{9,10}$ The $\beta$-cell associated changes in the secretion of insulin initiates the cellular signaling cascade. Activation of advanced glycation end products, stimulation 
of Di-acyl glycerol kinase pathway and oxidative stress reduces the $\beta$-cell functioning.

The currently available anti-diabetic drugs used to treat Type-II DM are associated with potential adverse effects. ${ }^{11,12}$ Excessive insulin release by widely used anti-diabetic drugs like sulfonylureas causes hypoglycemia. ${ }^{13}$ Similarly, use of peroxisome proliferator-activated receptor (PPAR- $\gamma$ ) agonists is associated with weight gain, fluid retention, urinary bladder cancer, osteoporosis and cardiovascular complications. ${ }^{14}$ Rosiglitazone is PPAR agonist and widely used anti-diabetic drug. It acts primarily through the activation of AMP-activated protein kinase (AMPK) and its use is associated with weight gain and edema. Similarly, the antidiabetic effect of metformin exhibits the partial involvement of AMPK and shows the associated adversities. Despite promising preclinical results, the drug 5-Aminoimidazole-4-carboxamide nucleotide failed to demonstrate its efficacy in phase I clinical trial. Due to safety concerns, many promising molecules like dual-acting PPAR $\gamma / \alpha$ or pan modulators of PPAR are still awaiting the US Food and Drug Administration (FDA) approval. Remedial approaches for the management of Type-II DM are aimed to delay the onset of complications following treatment with antidiabetic drugs. The search for more efficacious and safer antidiabetic agents is an active area of research. Newer drugs lacking the adverse effects of conventional antidiabetics and having ability to control hyperglycemia are critically needed. Incidence of Type-II DM can be minimized by identification of risk factors responsible for its occurrence. Understanding of mechanisms of actions of antidiabetic drugs, signaling pathways and therapeutic targets of Type-II DM can guide the development of clinically useful antidiabetic drugs. Present review provides an overview of underlying mechanisms of action of antidiabetic drugs. This paper also contains information on promising therapeutic targets of Type-II DM evolved from pharmacological and molecular studies.

\section{Promising therapeutic targets}

The treatment of Type-II DM and management of diabetic complications is a complex area of therapy. Limited treatment opportunities and shortage of therapeutic agents used to delay the diabetic complications are main hurdles in the treatment of Type-II DM. This therapeutic mystery can be resolved by the identification of novel therapeutic targets and development of new drugs. Postprandial euglycemia is maintained by gut-derived peptide hormones (incretins), glucagon-like peptide-1 (GLP-1) (neuropeptide) and gastric inhibitory polypeptide/glucose-dependent insulinotropic peptide (GIP) through the stimulation of insulin secretion. Dipeptidyl peptidase-IV (DPP-IV) is a protease enzyme responsible for degradation of incretins. Inhibition of DPP-IV prevents the degradation of incretins, GLP-1 and GIP. It leads to elevated lowering of blood glucose level and control of hyperglycemia. ${ }^{15}$ Alogliptin is selective DPP-IV inhibitor approved by FDA for the treatment of Type-II DM in 2013. Development of insulin resistance in humans and rodents is a consequence of abnormal or overexpressed glycogen synthase kinase 3 (GSK-3). Two isozymes of GSK-3 that is, GSK-3 $\alpha$ and GSK-3 $\beta$ are present in mammals. GSK-3 $\beta-2$ is an alternative splice variant of GSK-3 $\beta .{ }^{16}$ Although, GSK-3 $\alpha$ and GSK- $3 \beta$ have close similarity in their catalytic domains, they differ at their $\mathrm{N}$ - and C-terminal regions. ${ }^{17}$ Selective GSK-3 inhibitors demonstrated their efficacy in animal models of Type-II DM through the increased insulin action in insulinresistant skeletal muscle. ${ }^{18}$ Identification and understanding of therapeutic targets in Type-II DM is essential for the designing of therapeutic strategy. Various therapeutic targets in Type-II DM are summarized in Tables 1 and 2.

\section{SIRT-I: insulin resistance and insulin availability}

SIRT-1 refers to sirtuin (silent mating type information regulation 2 homolog)-1. It is a member of sirtuin protein family known as nicotinamide adenine dinucleotide (NAD) dependent histone deacetylase, which is preserved in evolution from bacteria to humans. ${ }^{19}$ In human, seven different types of sirtuin are present. SIRT-1 is a protein deacetylase present in the cytoplasm and nucleus of cell. SIRT-1 is widely studied for its effects in various metabolic disorders. SIRT-1 utilizes oxidized NAD as a cofactor and is negatively regulated either by nicotinamide adenine dinucleotide or its deacetylation product nicotinamide. ${ }^{20}$ SIRT-1 deacetylates various substances, including uncoupling protein 2 (UCP-2) and peroxisome proliferator activated receptor gamma coactivator $1 \alpha($ PGC-1 $\alpha)$. SIRT-1 also exhibits control over metabolic tissues such as skeletal muscles, liver and adipose tissues..$^{21}$ The UCP2 is a specific uncoupling protein present in the inner membrane of brown adipocytes's mitochondria and acts as negative regulator of insulin secretion. However, PGC- $1 \alpha$ is the main regulator of glucose production in the liver that controls the entire gluconeogenic pathway. ${ }^{22}$ Interestingly, SIRT-1 is prominently expressed in $\beta$-cells of pancreas. SIRT-1 regulates the insulin secretion and sensitizes the peripheral tissues to the action of insulin..$^{23,24}$ SIRT-1 regulates the PPAR- $\gamma$ expression and thereby controls the process of adipogenesis and fat storing in the adipose tissues. ${ }^{25}$ Additionally, SIRT-1 plays an important role in the differentiation of muscle cells and regulation of metabolism in the liver. Therefore, extensive involvement of SIRT-1 


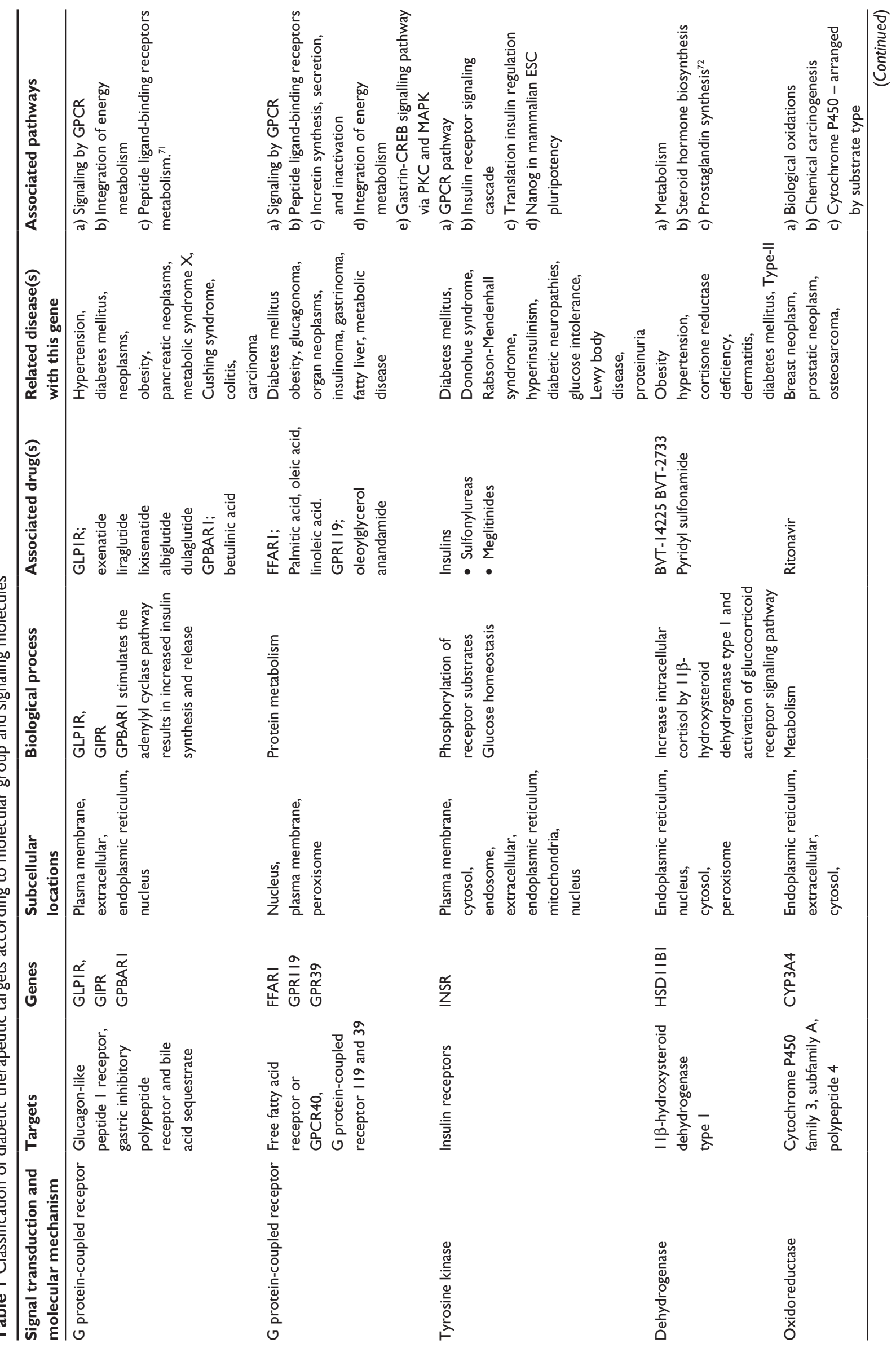




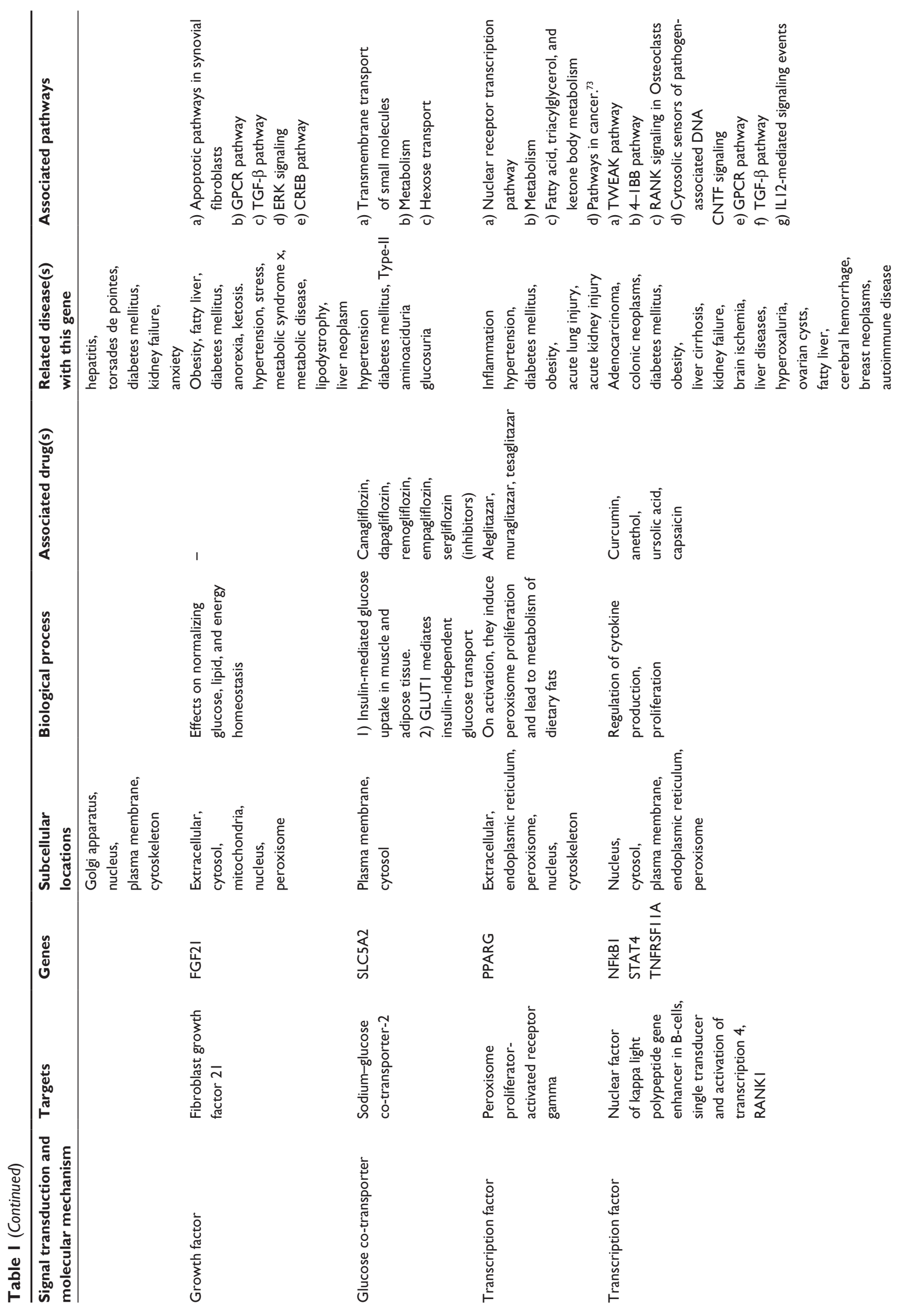



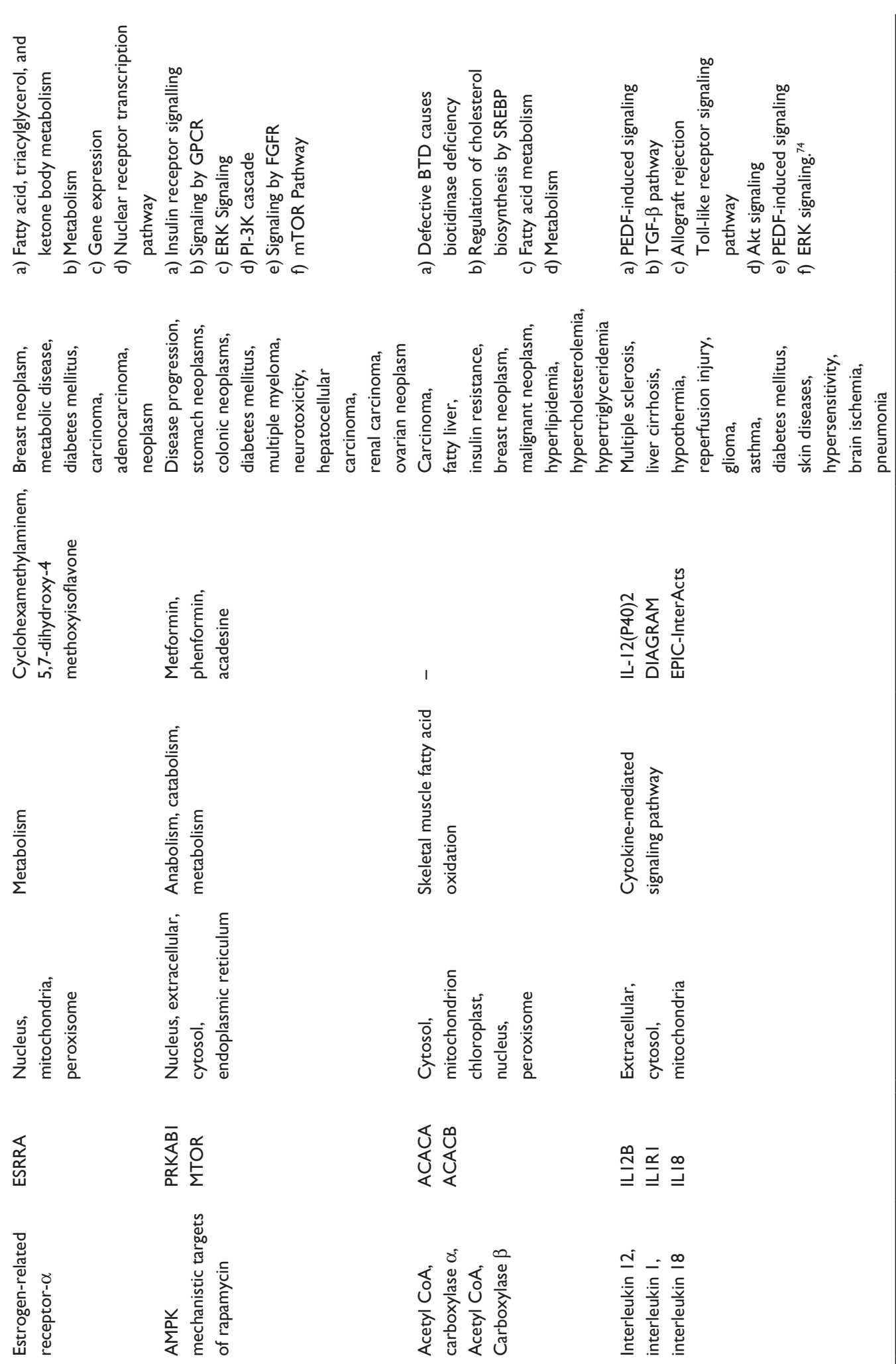

要尔

它谣

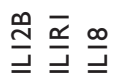
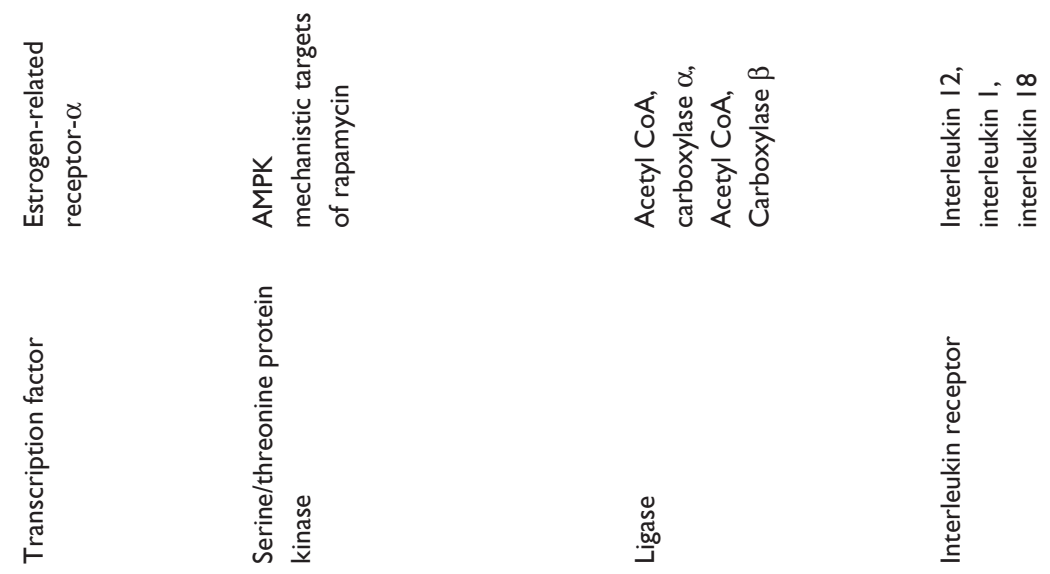


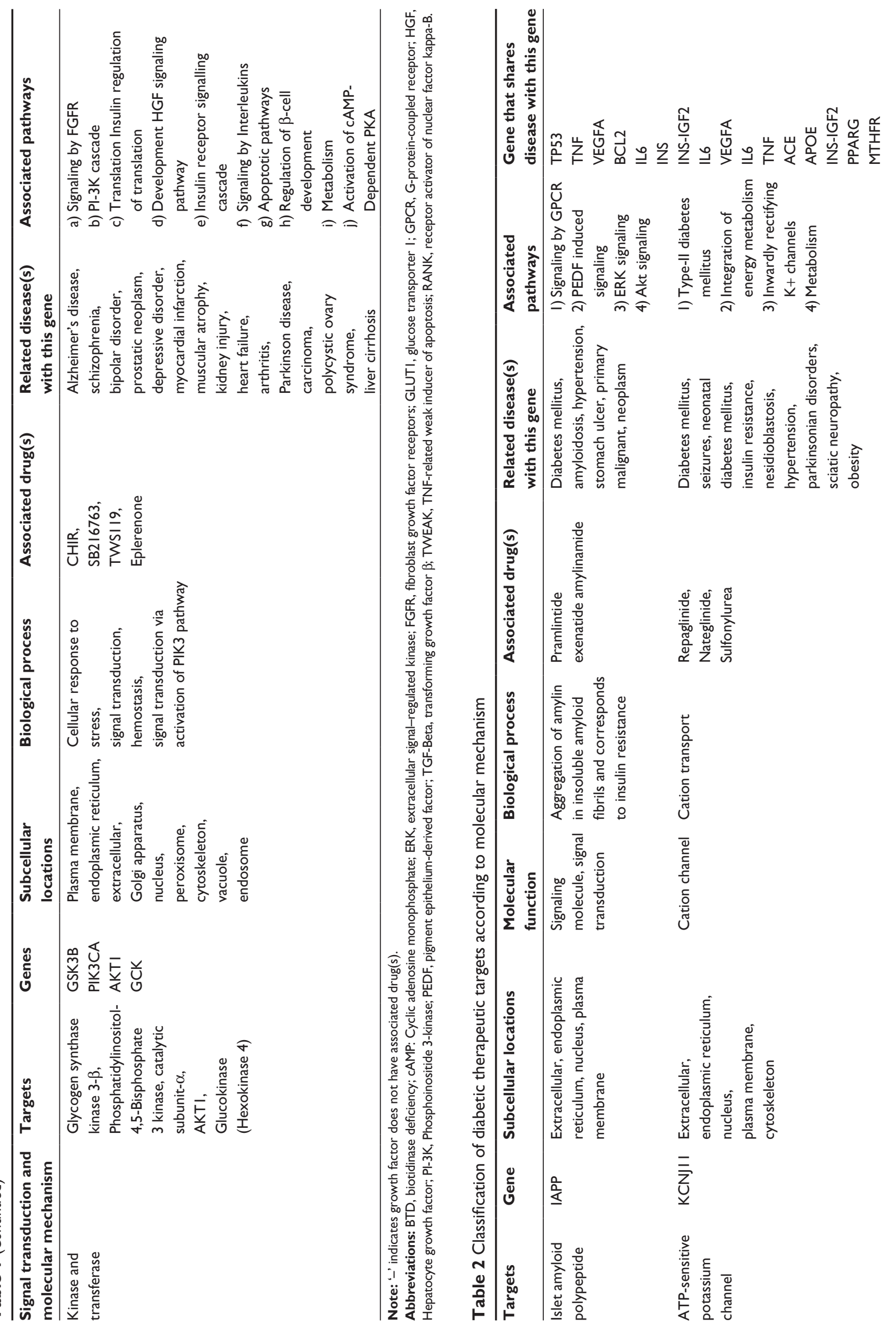




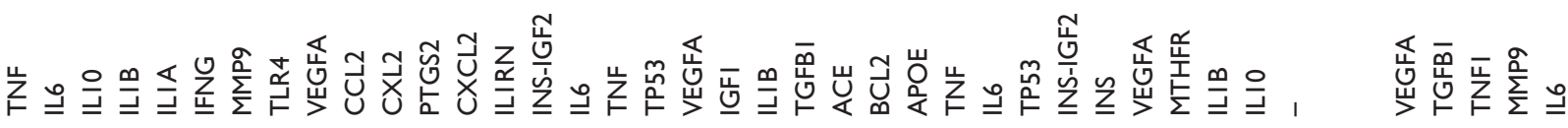
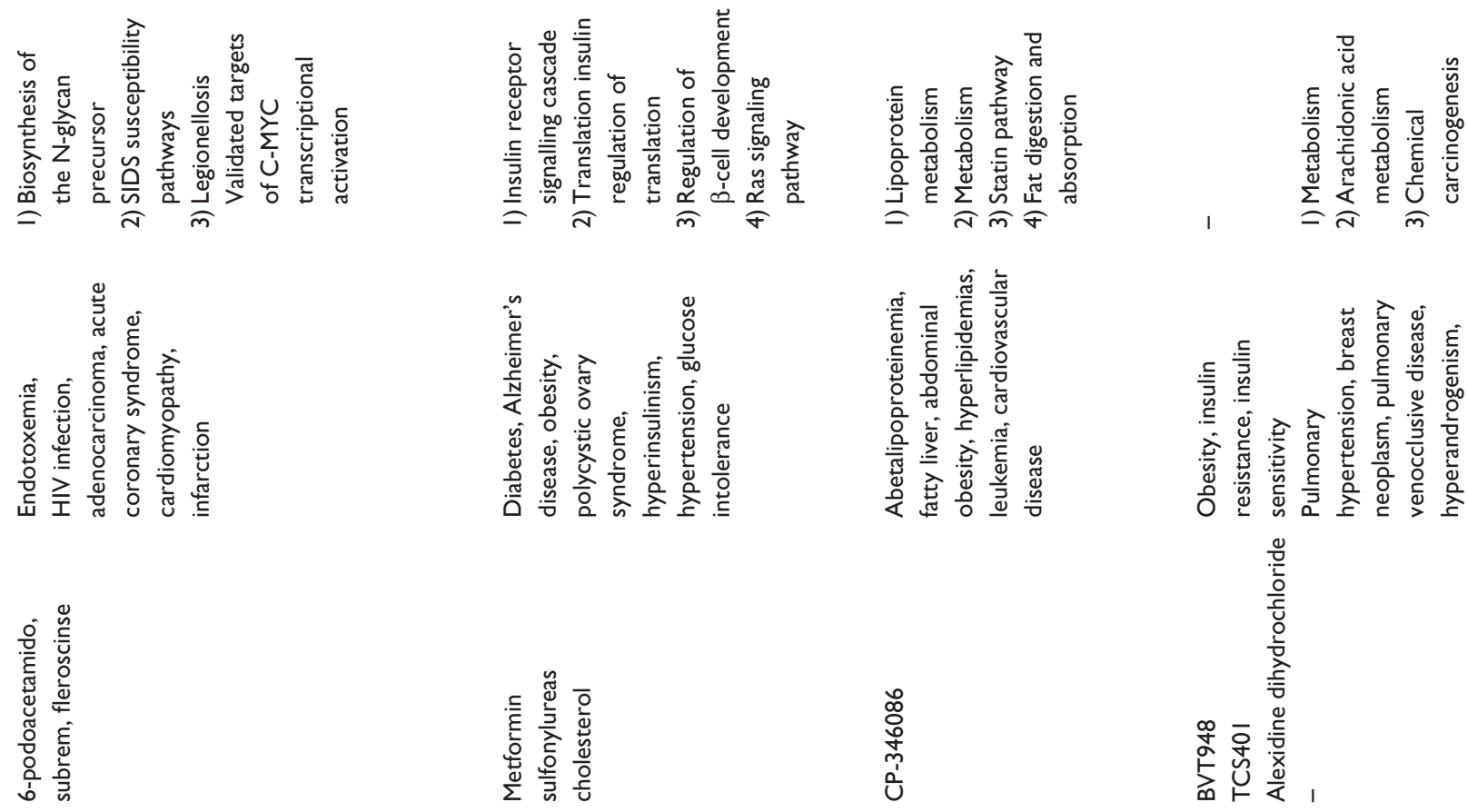

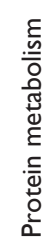

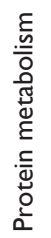
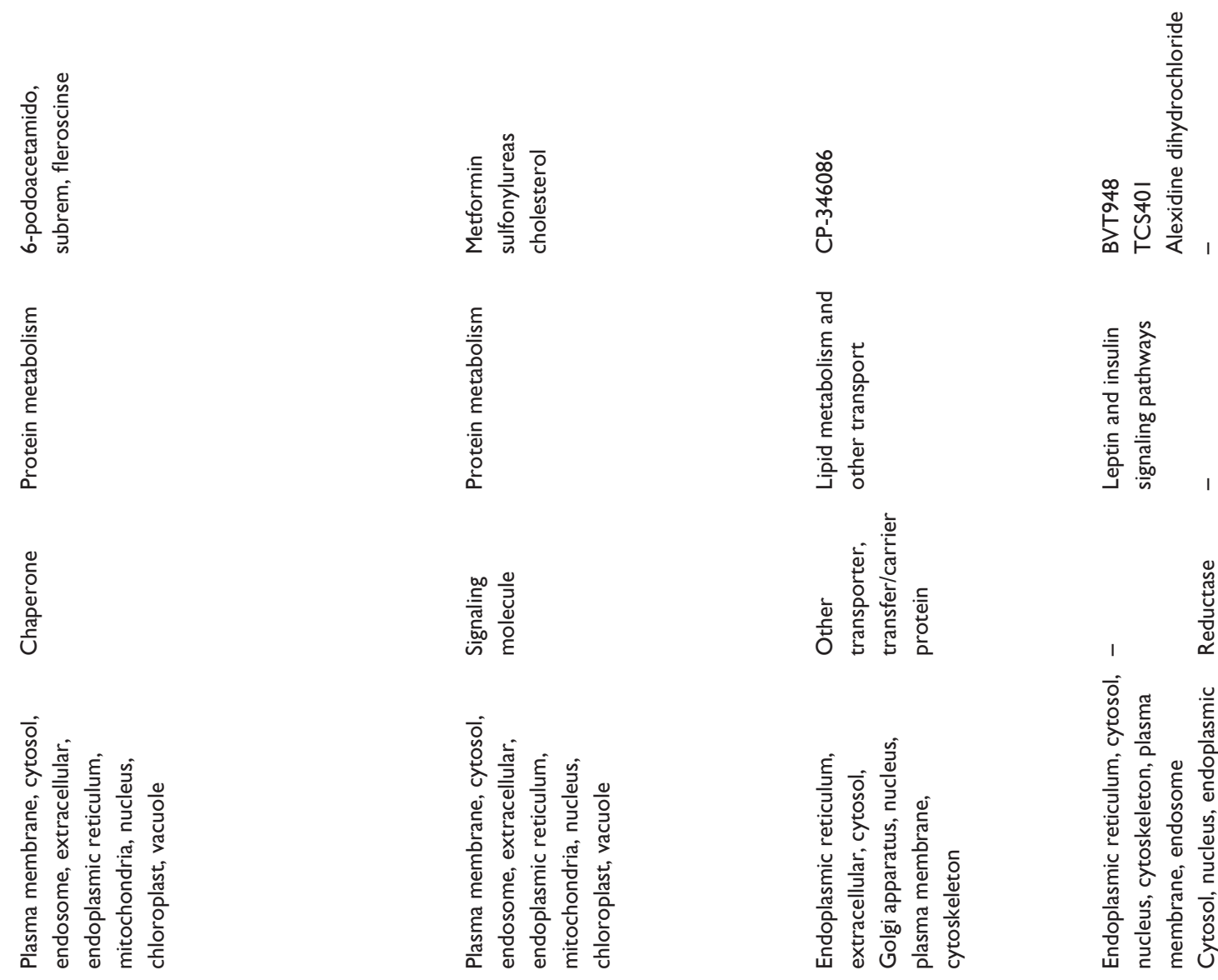

$\overline{0}$
$\frac{0}{0}$
⿱ㅗ

$\stackrel{\text { E }}{\Sigma}$
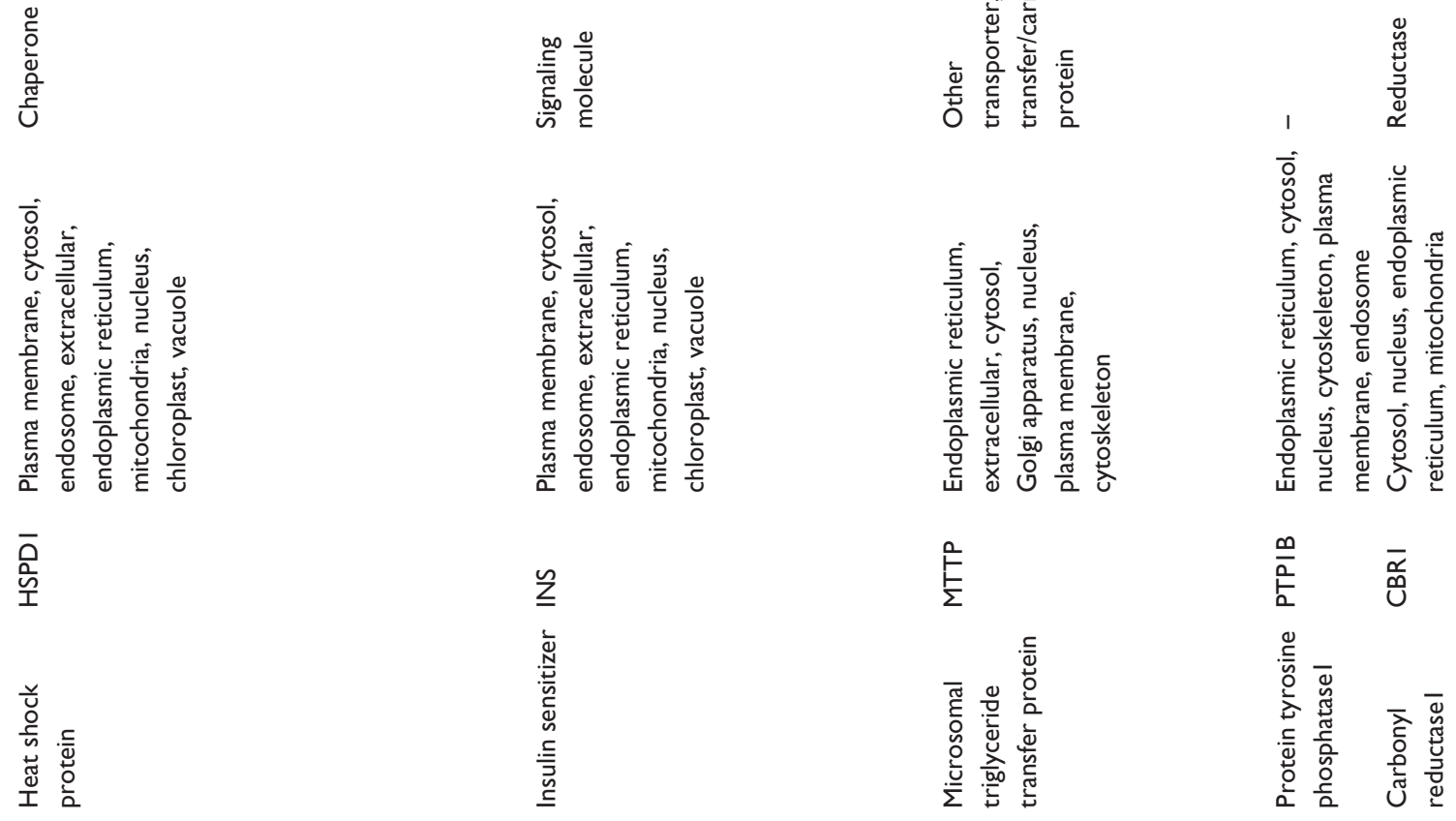


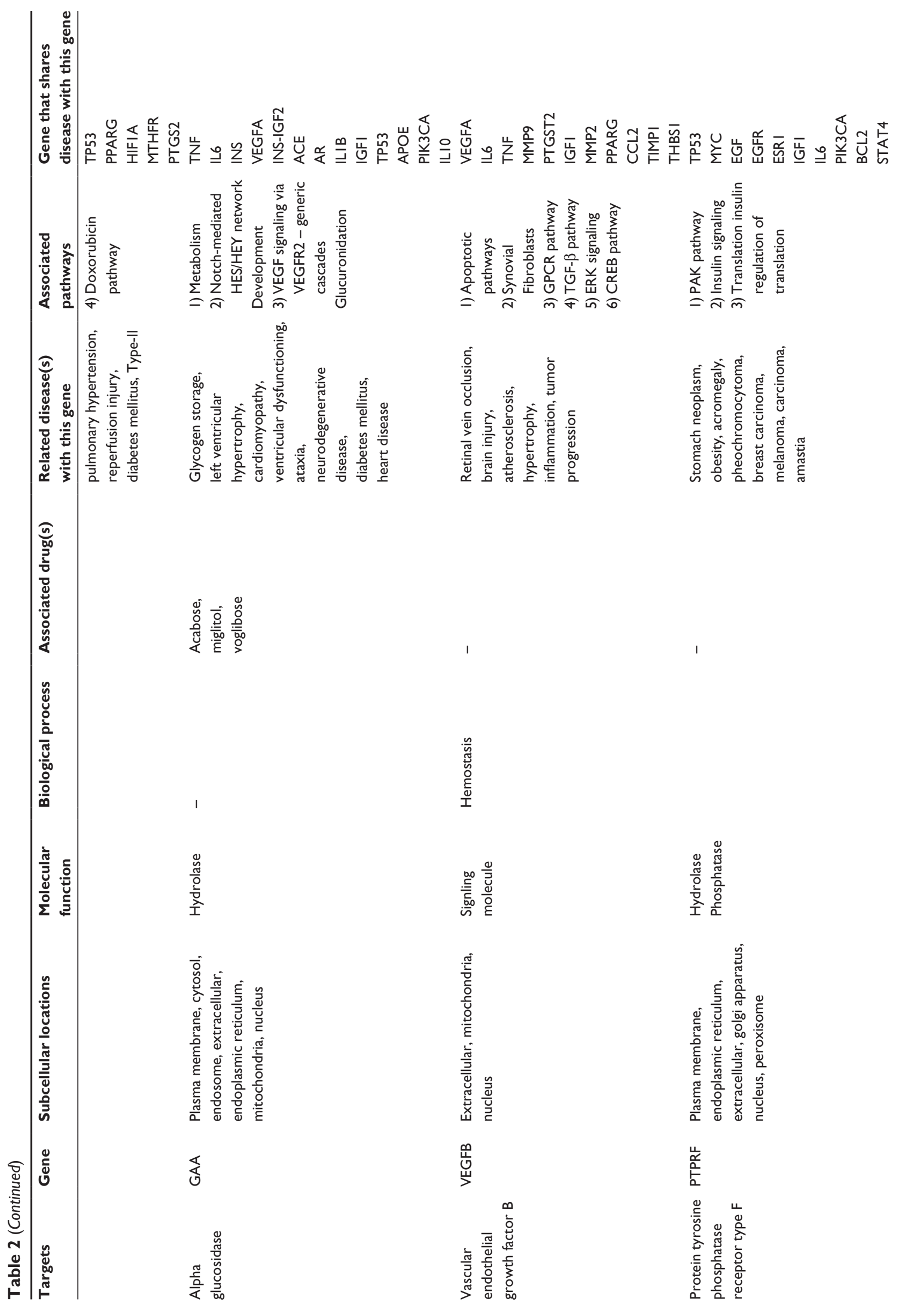




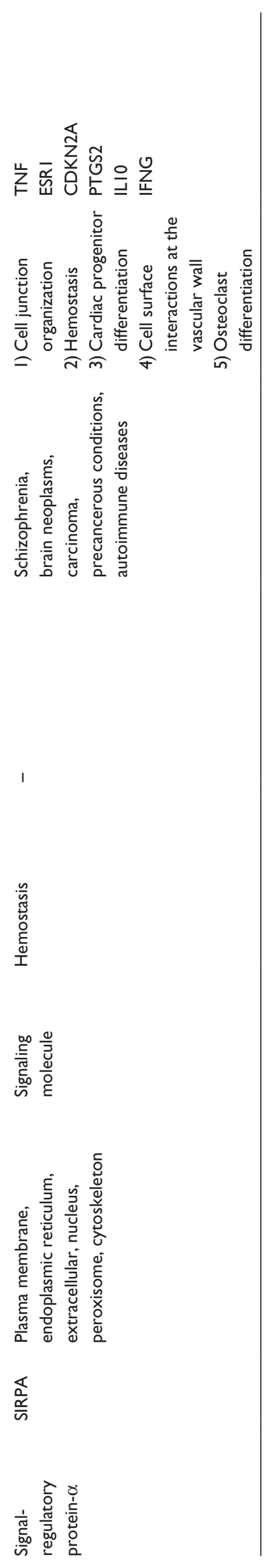

in the control and regulation of insulin action describes its significance as a therapeutic target in Type-II DM.

\section{SIRT-I: overproduction of ATP}

SIRT-1 is located in the cytoplasm and nucleus of pancreatic $\beta$-cells. Moynihan et al observed that suppression of UCP-2 due to over expression of SIRT-1 in pancreatic $\beta$-cells of mice enhances the production of ATP. ${ }^{26}$ SIRT- 1 increases the insulin secretion with some reduction in the glycolytic flux. The oxidative phosphorylation and suppression of mitochondrial UCP-2 uncoupling were proposed as the cause of elevated ATP levels. Whereas, Guarente and Kenyon $^{27}$ observed that decreased SIRT-1 activity and elevated mitochondrial protein UCP-2 level causes significant reduction in the ATP production. PGC- $1 \alpha$ is a transcriptional co-activator that favorably modulates the glucose-stimulated insulin secretion through the stimulation of activity of gluconeogenic genes and suppression of activity of glycolytic genes. The $\beta$-cells of pancreas secrete both SIRT-1 and PGC- $1 \alpha$ in small quantities. Gerhart Hines et $\mathrm{al}^{28}$ reported that SIRT-1 causes activation of PGC- $1 \alpha$ and exhibits inhibitory effect on glucose metabolism in liver. Sirtuin agonists enhance the metabolic efficiency through increased insulin secretion and/or improved insulin sensitivity. ${ }^{29,30}$ Sirtuin causes the extension of life span and improvement of metabolism in simple organisms. It suggests the role of sirtuin pathway as a therapeutic target in metabolic diseases. However, rigorous genetic tests that need to confirm the ability of sirtuin as modulator of metabolism are still awaited.

\section{Protein tyrosine phosphatase IB: a dynamic player in insulin resistance}

Protein tyrosine phosphatase 1B (PTP1B), belongs to the family of PTP enzymes encoded by Ptpn 1 gene. It is a ubiquitously expressed, monomeric enzyme having 435 amino acids with molecular weight of $50 \mathrm{kDa}{ }^{31,32}$ Dephosphorylated PTP1B regulates the important cell signaling events during cell growth, differentiation and apoptosis. ${ }^{32}$ Structurally, the N-terminal domain of PTP1B consists of two aryl phosphatebinding sites namely a high-affinity catalytic site that contains the nucleophile cysteine residue and low-affinity non-catalytic site containing the Arg24 and Arg254 residues. ${ }^{33}$ Whereas, the $\mathrm{C}$-terminal domain of PTP1B includes proline residues and the hydrophobic amino acid residues 400-435. These residues are responsible for locating PTP-1B at the cytoplasmic phase of the endoplasmic reticulum. ${ }^{34}$ In insulin signaling pathway, PTP1B dephosphorylates several substrates such as tyrosine residues 1,162 and 1,163 , which causes subsequent termination of receptor tyrosine kinase cascade. 
The binding of insulin to the insulin receptor (IR) phosphorylates the IR subunit 1 and causes the down-regulation of insulin signaling pathway. ${ }^{35}$ Moreover, PTB1B controls the interaction between $\mathrm{IRS}_{1}$ and $\mathrm{IRS}_{2}$, which modulates the hepatic insulin action and insulin sensitivity. ${ }^{36}$ Thus, PTB1B plays a vital role in the insulin resistance and it is one of the important therapeutic targets in Type-II DM.

\section{PTPIB inhibitors}

It is evident that decreased PTP1B activity is related to increased insulin activity, which has a protective effect in diabetes. ${ }^{37}$ The PTP1B is a negative regulator of insulin signaling. The ability of PTP1B inhibitors to prolong the actions of insulin denotes their potential in the management of Type-II DM. ${ }^{38}$ Ertiprotafib belongs to the class of compounds that potently inhibit the PTP1B activity and normalizes plasma glucose and insulin levels in genetically diabetic and/or obese animals in experimental models of Type-II DM. ${ }^{39}$ One of the synthetic tris-sulfotyrosyldodecapeptides inhibited the IR dephosphorylation and enhanced the insulin signaling in Chinese hamster ovary cells over expressing human IRs. ${ }^{40}$

\section{Sodium-glucose linked transporter (SGLT): role in glucose transport and regulation}

Type-II DM has complex and multifactorial pathophysiology. Decrease in insulin secretion by pancreatic $\beta$-cells due to development of insulin resistance is the hallmark of Type-II DM. The insulin resistance in liver, brain and muscle leads to increased glucagon secretion, lipolysis and increased absorption of glucose by nephrons. Glucose is a vital source of energy for carrying out various cellular and metabolic processes. Lipoidal nature of cell membrane restricts the entry of polar glucose to extracellular region. Glucose is transported via two types of glucose transporters namely glucose transporter (GLUT) transporter and sodium-glucose transporter (SGT). There are 14 different types of GLUT transporters and 7 types of SGT are characterized. The GLUT transporter protein is a 12 membrane-spanning helical structure having amino and carboxyl terminals that are exposed on the cytoplasmic side of the plasma membrane. GLUT facilitates passive transport of glucose according to concentration gradient. In contrast, sodium glucose co-transporter involves the active transfer of glucose across the cell membrane against concentration gradient at the use of energy. Among various types of SGLT, only SGLT-1 and SGLT-2 facilitate the reabsorption of glucose into the plasma. Thus, inhibition of this process is proposed to decrease the blood glucose level and promote glucosuria. The kidney plays an important role in the glucose homeostasis. In a healthy adult, about 180-190 g of glucose per day is filtered from the glomeruli. ${ }^{41}$ Out of this filtered glucose, about 95\% is reabsorbed through SGLT and circulatory glucose levels are maintained. ${ }^{42}$ The up-regulation of SGLT-2 in Type-II DM causes increased transportation of glucose and subsequent hyperglycemia.

\section{SGLT-2 inhibition: a prospect to amend our therapeutic strategy}

It is well established that inhibition of glucose reabsorption from kidney tubules improves the glucose homeostasis. ${ }^{43}$ Recently, SGLT-2 inhibitors demonstrated their effect on glycemic control in animal models of diabetes as well as Type-II DM patients. ${ }^{44}$ Clinical evidence for dual inhibition of SGLT-1 and SGLT-2 is available. ${ }^{45}$ SGLT-1 is the chief intestinal glucose transporter that reabsorbs about $10 \%$ of total renal glucose. ${ }^{46}$ Functional deficit of SGLT-1 leads to glucose malabsorption, which is exhibited by gastrointestinal symptoms. ${ }^{47}$ As SGLT-1 inhibition is associated with glucose malabsorption, selective SGLT-2 inhibitors were developed to avoid the SGLT-1-induced malabsorption state. SGLT-2 inhibitor decreases renal glucose reabsorption, increases urinary glucose excretion, improves the peripheral insulin sensitivity and enhances pancreatic $\beta$-cell function to maintain blood glucose levels. ${ }^{48,49}$

Besides control of blood glucose level, SGLT-2 inhibitors also reduce blood pressure, body weight and lower the risk of hypoglycemia. ${ }^{50}$ The glucose-lowering effect of SGLT-2 inhibitors is comparable with the effect of metformin and dipeptidyl peptidase-4, (DPP-4) inhibitors when used as monotherapy. Thus, SGLT-2 inhibitors are suggested as alternative first-line therapeutic agents when metformin cannot be used. The first SGLT-2 inhibitor, canagliflozin was approved by the FDA in March 2013. ${ }^{51}$ Canagliflozin was studied in Type-II DM patients and compared clinically with standard antidiabetic drugs like metformin, glimepiride, sitagliptin, pioglitazone, etc. In phase III trial, canagliflozin at the dose of $100 \mathrm{mg}$ and $300 \mathrm{mg}$ showed the favorable effects in Type-II DM patients. Following the approval of canagliflozin, another SGLT-2 inhibitor, dapagliflozin is approved by the FDA for use in adults with Type-II DM in January $2014 .{ }^{52}$ The clinical efficacy and safety of the dapagliflozin as a SGLT-2 inhibitor were extensively studied using 14 clinical trials and evidence is widely documented. ${ }^{53-55}$ Similarly, other molecules such as ipragliflozin and ertugliflozin are in development pipeline and currently at phase III trials. ${ }^{56}$ 


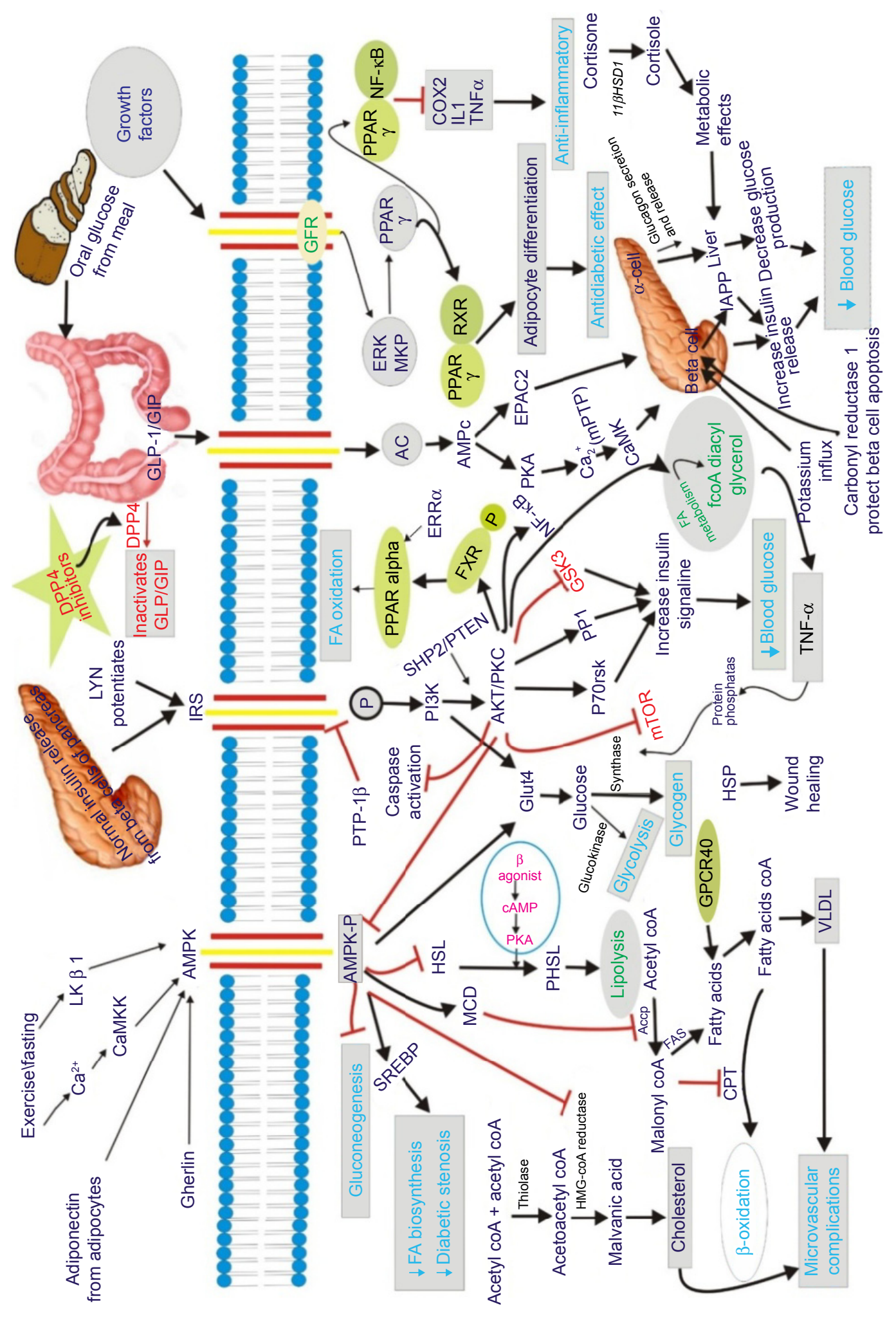

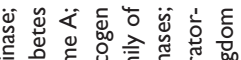

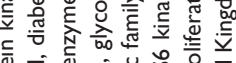

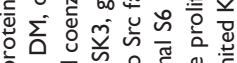

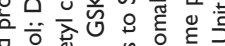

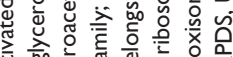

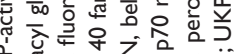

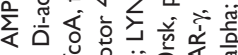

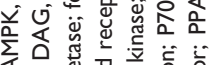

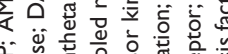

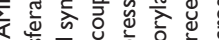

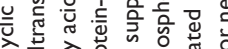

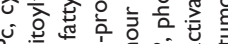

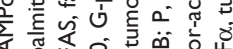

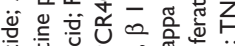

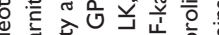

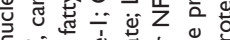

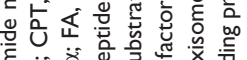

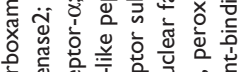

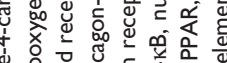

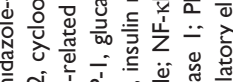

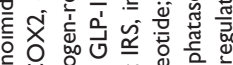

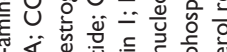

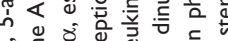

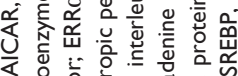

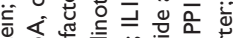

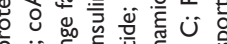

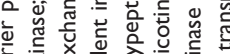

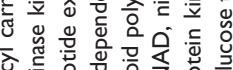

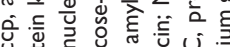

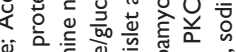

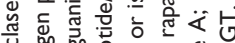

U人.

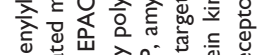

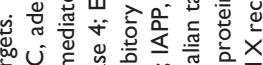

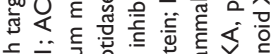

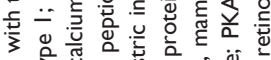

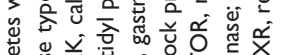

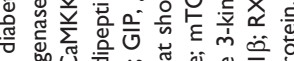

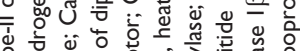

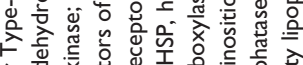

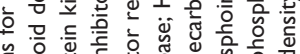

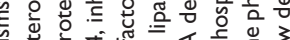

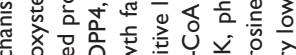

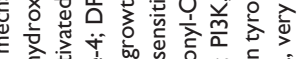

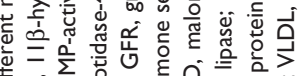

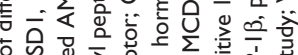

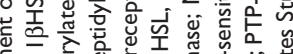

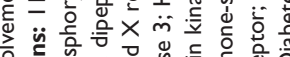

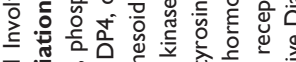

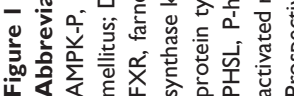




\section{GSK-3: constructive treats}

Glycogen synthase, is a rate limiting enzyme involved in glycogen biosynthesis. GSK-3 was identified in the late 1970 s, and possesses an ability to phosphorylate the glycogen synthase. ${ }^{57,58}$ The GSK-3 is conserved signaling molecule that belongs to serine/threonine kinases. It has an important role in diverse biological processes. It was observed that abnormal GSK-3 activity is associated with multiple human pathologies such as diabetes, psychiatric diseases, neurodegenerative and inflammatory diseases. ${ }^{59}$ This observation laid down the foundation of hypothesis that GSK-3 inhibition has therapeutic benefits in various ailments. It has directed the research toward the discovery and design of selective GSK-3 inhibitors. The reported GSK-3 inhibitors include small molecules isolated from natural and marine sources or obtained from chemical synthesis. These inhibitors may act through multiple mechanisms, including competitive or non-competitive inhibition of ATP. Academic and industrial efforts have been made toward the discovery and development of novel GSK-3 inhibitors. ${ }^{60}$ Several chemical families with great structural diversity are reported to emerge as GSK-3 inhibitors. The number of small molecule GSK-3 inhibitors is on continuous rise and most of these inhibitors are in the early discovery phase.

\section{Phosphatidylinositol 3-kinase/Akt}

Phosphatidylinositol 3-kinase (PI3K) and its downstream effector, serine-threonine protein kinase (Akt) are chief signaling enzymes implicated in cell survival and metabolic control. ${ }^{61,62}$ The phosphorylation of downstream apoptotic molecules such as BAX, Bcl-2-associated death promoter (BAD) and GSK-3 $\beta$ by $\mathrm{PI} 3 \mathrm{~K} / \mathrm{Akt}$ elicit potent anti-apoptotic effect. The PI3K/Akt pathway is responsible for insulin-mediated glucose metabolism as well as protein synthesis and inactivation of its downstream target GSK-3, which is crucial for glucose sensing and $\beta$-cell growth. ${ }^{63}$ Thus, GSK-3 $\beta$ can be the possible target for $\beta$-cell protective agents. ${ }^{64}$ Wortmannin, an antagonist of PI3K through down-regulation of PI3K/Akt signaling, inhibited the cell proliferation and induced the apoptosis. ${ }^{65}$ Different mechanisms and biological targets involved in Type-II DM are presented as Figure 1 and Table 3.

\section{Discontinued drugs}

Diabetes is the 6th major cause of worldwide deaths. ${ }^{66}$ Alarming increase in the incidence of diabetes demands for successful therapies. American biopharmaceutical research organizations are engaged in the development of about 180 new medicines for diabetes and related conditions. Currently, about 200 clinical trials on diabetic patients are ongoing in USA. Promising leads from the development pipeline have shown a hope for the control of diabetes complications at an affordable cost. However, failure of drugs to demonstrate promising results in the clinical trials and incidences of market withdrawal have resulted in the decline in interest of major pharmaceutical companies in diabetes research. In between 2012 and 2013 and in 2014, 22 and 14 antidiabetic drugs were discontinued from various phases of drug development. Details of these discontinued drugs are described in Table 4. Piramal Life Sciences discontinued the development of three antidiabetic drugs namely, P-11187, P-1736-05 and $\mathrm{P}-7435$ in 2014 . The $\mathrm{P}-11187$ is G-protein-coupled receptor 40 (GPCR40) agonist, which showed promising results in Type-II diabetes. It acts through the stimulation of glucoseinduced insulin secretion. ${ }^{67} \mathrm{P}-11187$ was described as an oral, highly selective and potent partial agonist of human, rat and

Table 3 Distribution of therapeutic targets of diabetes mellitus

\begin{tabular}{llll}
\hline Molecular function & No of targets & Biological process & No of targets \\
\hline Tyrosine kinase & $\mathrm{l}$ & Phosphorylation & $\mathrm{I}$ \\
Dehydrogenase & $\mathrm{I}$ & Lipid metabolism & $\mathrm{I}$ \\
Growth factor & $\mathrm{I}$ & Homeostasis & 2 \\
Transport & 2 & Insulin resistance & 2 \\
Serine/threonine kinase & 2 & Transport and uptake & 2 \\
Ligase & 2 & Fatty acid oxidation & 2 \\
Transfer carrier protein & 2 & Insulin release & 3 \\
Oxidoreductase & 2 & Signal transduction & 4 \\
Signaling molecule & 3 & Protein metabolism & 5 \\
Interleukin receptor & 3 & Cytokine mediated & 5 \\
Transcription factor & 4 & Other metabolism & 5 \\
Hydrolase and protease & 4 & & \\
G-protein-coupled receptor & 5 & & \\
Kinase/Transferase & 7 & & \\
\hline
\end{tabular}




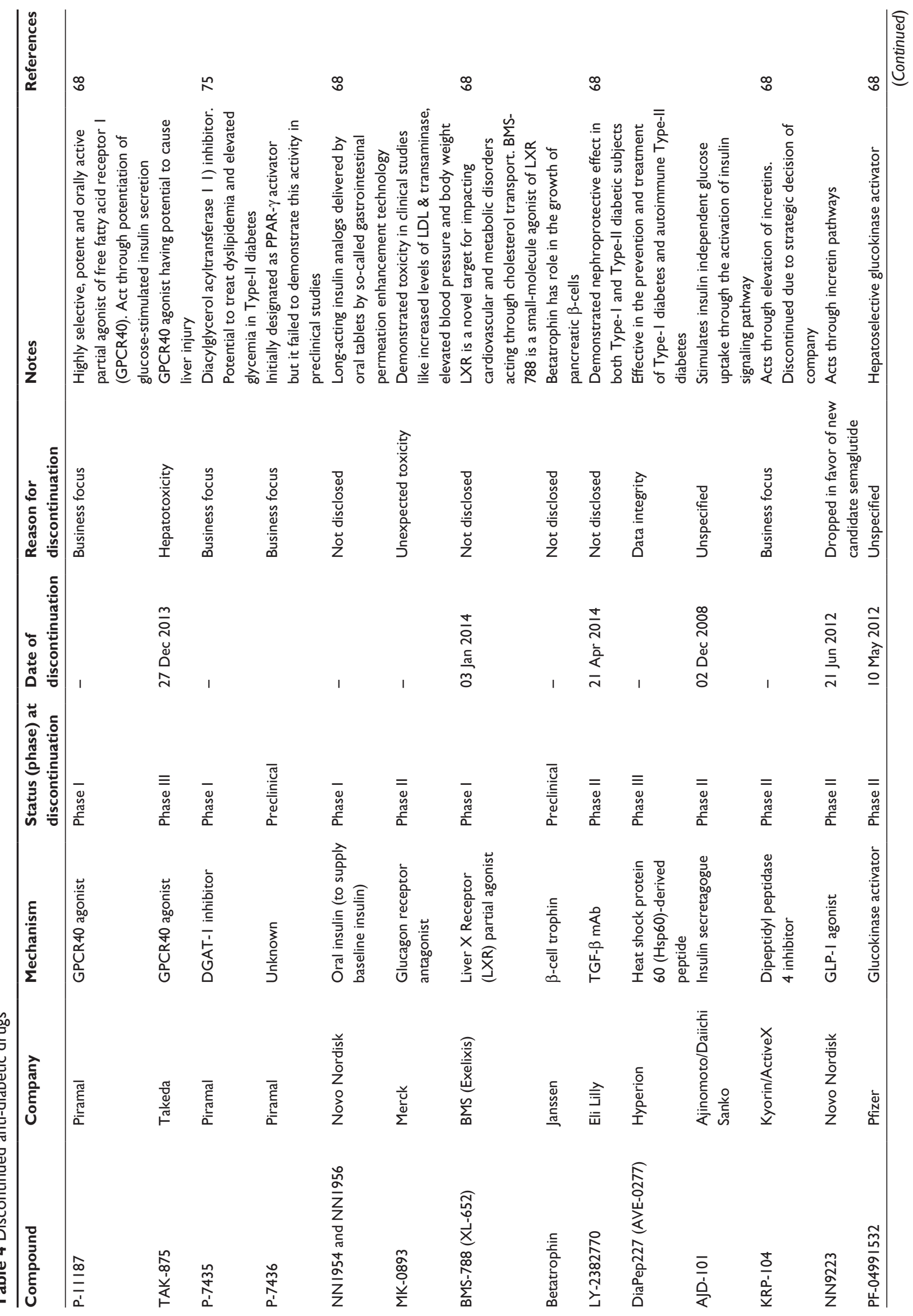




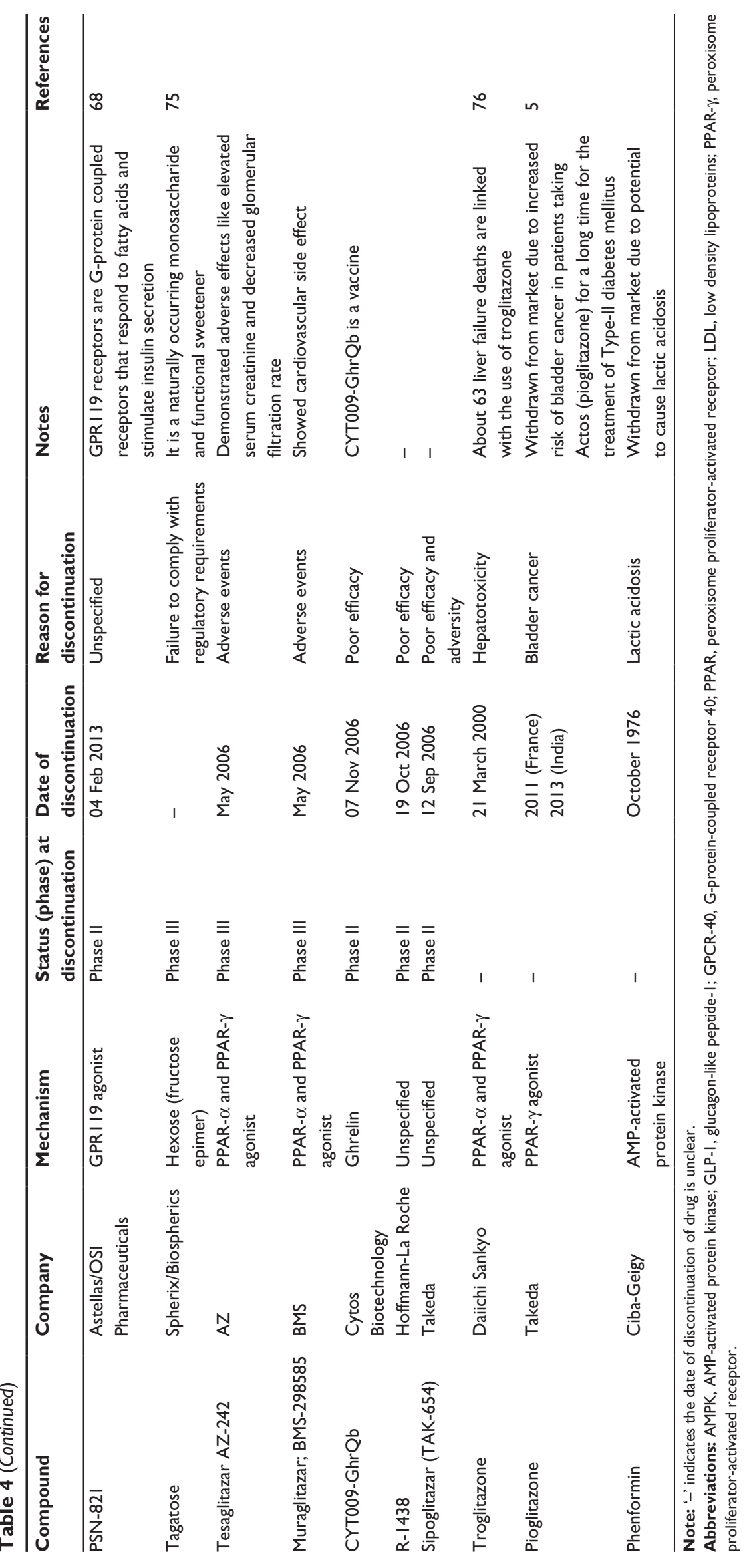


mouse GPCR40 with effective concentration $50\left(\mathrm{EC}_{50}\right)$ value of 14.4, 2.53 and $4.25 \mathrm{nM}$, respectively. ${ }^{68} \mathrm{P}-1736-50$ was considered as a PPAR- $\gamma$ activator, but in preclinical studies, it failed to demonstrate its efficacy and hence was discontinued from further research. Piramal Life Sciences also discontinued the development of diacylglycerol acyltransferase 1 inhibitor P-7435 due to business focus. Similarly, Takeda discontinued TAK-875 (Fasiglifam) due to its hepatotoxic potential in phase III clinical trial. The MK-0893 is another molecule discontinued from the development process by Merck due to safety issues. Glucokinase is a major enzyme that phosphorylates glucose into glucose-6-phosphate. It is essential for glycogenesis and plays an important role in the hepatic glucose clearance. In 2013, Takeda was developing TAK-329 as glucokinase activator, but due to unexpected reasons, Takeda discontinued the development of this drug. Glucagon-like peptide 1 (GLP-1) and GIP are produced in intestine. The active forms of GLP and GIP increase the insulin secretion and regulate the glucose homeostasis. Upon release, GLP and GIP are immediately inactivated by dipeptidyl peptidase-4 (DP4) hence they have very short half-life. ${ }^{69}$ Therefore, the discovery of DP4 inhibitors is a promising approach toward the development of novel antidiabetic drugs. The SYR-472 was a highly selective, long active DP4 inhibitor from Takeda that was discontinued due to its high development cost. Recently, Takeda has discontinued the development of combined PPAR- $\gamma / \alpha$ activator, sipoglitazar in phase III. ${ }^{70}$ Various anti-diabetic drugs that are discontinued from further research or withdrawn from the market are described in Table 4.

\section{Conclusion}

Scientific studies encircling the diabetes and its complications are on continuous rise. The annual cost of diabetes to the USA health care system is $\$ 100$ billion. Despite the availability of numerous antidiabetic drugs, search for the novel leads that completely cure Type-II DM is an ongoing quest. The disease architecture in Type-II DM is so complicated that even magic bullets, which selectively target one protein, fail to restore the biological network to healthy state. The current research scenario highlighted the need for identification and exploration of therapeutic targets in Type-II DM. Successful modulation of these biological targets can result in the cure of diabetes and associated complications. The present review provides an overview of therapeutic targets and their role in Type-II DM. This information can be used to plan the therapeutic strategies for the management of Type-II DM.

\section{Search strategy}

We searched data bases like PubMed, Medline, Google Scholar, Science Direct, Gene cards and DisGenNET along with proceedings available on websites of the American Diabetes Association and European Association for the Study of Diabetes. Full text articles published between 1980 and 2016 and written in English are included in present review. Databases were searched with keywords like names of target, gene, discontinued drugs, drugs withdrawn from market and inhibitors in development.

\section{Acknowledgments}

The authors gratefully acknowledge the financial support received under Young Scientist Research Scheme (File no SB/YS/LS-114/2013) of Science and Engineering Research Board (SERB), Department of Science and Technology, New Delhi, India. Also, the research support from the University Program for Advanced Research (UPAR) and Center-Based Interdisciplinary grants from the Office of the Deputy Vice Chancellor of Research and Graduate Studies of United Arab Emirates University, Al Ain, UAE to Shreesh Ojha is gratefully acknowledged.

\section{Disclosure}

The authors report no conflicts of interest in this work.

\section{References}

1. Mali A, Bhise S, Katyare SS. Omega-3 fatty acids and diabetic complications. Omega-3 fatty acids. Springer. 2016:221-227.

2. Guariguata L, Whiting D, Hambleton I, Beagley J, Linnenkamp U, Shaw J. Global estimates of diabetes prevalence for 2013 and projections for 2035. Diab Res Clin Pract. 2014;103(2):137-149.

3. Hassanzadeh V, Mehdinejad MH, Ferrante M, et al. Association between polychlorinated biphenyls in the serum and adipose tissue with type 2 diabetes mellitus: a systematic review and meta-analysis. Health Sci. 2016;5(9):13-21.

4. Rohner-Jeanrenaud F, Nogueiras R. Endocrine control of energy homeostasis. Mole Cell Endocrinol. 2015;418:1-2.

5. Bolen S, Feldman L, Vassy J, et al. Systematic review: comparative effectiveness and safety of oral medications for type 2 diabetes mellitus. Ann Intern Med. 2007;147(6):386-399.

6. Fox CS, Coady S, Sorlie PD, et al. Increasing cardiovascular disease burden due to diabetes mellitus. Circ. 2007;115(12):1544-1550.

7. Bandyopadhyay P. Cardiovascular diseases and diabetes mellitus Drug News Perspect. 2006;19(6):369-375.

8. Brownlee M. Biochemistry and molecular cell biology of diabetic complications. Nat. 2001;414(6865):813-820.

9. Stumvoll M, Goldstein BJ, van Haeften TW. Type 2 diabetes: principles of pathogenesis and therapy. Lancet. 2005;365(9467):1333-1346.

10. DeFronzo RA, Bonadonna RC, Ferrannini E. Pathogenesis of NIDDM: a balanced overview. Diabetes Res. 1992;15(3):318-368.

11. Phung OJ, Scholle JM, Talwar M, Coleman CI. Effect of noninsulin antidiabetic drugs added to metformin therapy on glycemic control, weight gain, and hypoglycemia in type 2 diabetes. JAMA. 2010;303(14): $1410-1418$. 
12. Tzoulaki I, Molokhia M, Curcin V, et al. Risk of cardiovascular disease and all cause mortality among patients with type 2 diabetes prescribed oral antidiabetes drugs: retrospective cohort study using UK general practice research database. Brit Med J. 2009;339:b4731.

13. Van Staa T, Abenhaim L, Monette J. Rates of hypoglycemia in users of sulfonylureas. J Clin Epidemiol. 1997;50(6):735-741.

14. Chinetti G, Lestavel S, Bocher V, et al. PPAR- $\alpha$ and PPAR- $\gamma$ activators induce cholesterol removal from human macrophage foam cells through stimulation of the ABCA1 pathway. Nat Med. 2001;7(1):53-58.

15. Aulinger BA, Bedorf A, Kutscherauer G, et al. Defining the role of GLP-1 in the enteroinsulinar axis in type 2 diabetes using DPP-4 inhibition and GLP-1 receptor blockade. Diab. 2014;63(3):1079-1092.

16. Ali A, Hoeflich KP, Woodgett JR. Glycogen synthase kinase-3: properties, functions, and regulation. Chem Rev. 2001;101:2527-2540.

17. Kaidanovich-Beilin O, Woodgett JR. GSK-3: functional insights from cell biology and animal models. Front Mol Neurosci. 2011;4:40.

18. Ring DB, Johnson KW, Henriksen EJ, et al. Selective glycogen synthase kinase 3 inhibitors potentiate insulin activation of glucose transport and utilization in vitro and in vivo. Diab. 2003;52(3):588-595.

19. Zillikens MC, van Meurs JB, Rivadeneira F, et al. SIRT1 genetic variation is related to BMI and risk of obesity. Diab. 2009;58(12):2828-2834.

20. Leibiger IB, Berggren PO. A SIRTain role in pancreatic beta cell function. Cell Metab. 2005;2(2):80-82.

21. Li M, Sun X, Hua L, et al. SIRT1 gene polymorphisms are associated with growth traits in Nanyang cattle. Mol Cell Probes. 2013;27(5-6): 215-220.

22. Puigserver P, Rhee J, Donovan J, et al. Insulin-regulated hepatic gluconeogenesis through FOXO1-PGC-1alpha interaction. Nature. 2003; 423(6939):550-555.

23. Sun C, Zhang F, Ge X, et al. SIRT1 improves insulin sensitivity under insulin-resistant conditions by repressing PTP1B. Cell Metab. 2007;6: 307-319.

24. Bordone L, Motta MC, Picard F, et al. Correction: Sirt1 regulates insulin secretion by repressing UCP2 in pancreatic beta cells. PLoS Biol. 2015;13(12):e1002346.

25. Finck BN, Kelly DP. PGC-1 coactivators: inducible regulators of energy metabolism in health and disease. Eur J Clin Invest. 2006; 116(3):615-622.

26. Moynihan KA, Grimm AA, Plueger MM, et al. Increased dosage of mammalian Sir2 in pancreatic beta cells enhances glucose-stimulated insulin secretion in mice. Cell Metab. 2005;2(2):105-117.

27. Guarente L, Kenyon C. Genetic pathways that regulate ageing in model organisms. Nat. 2000;408(6809):255-262.

28. Gerhart-Hines Z, Rodgers JT, Bare O, et al. Metabolic control of muscle mitochondrial function and fatty acid oxidation through SIRT1/PGC1alpha. EMBO J. 2007;26(7):1913-1923.

29. Haigis MC, Guarente LP. Mammalian sirtuins - emerging roles in physiology, aging, and calorie restriction. Genes Dev. 2006;20(21): 2913-2921.

30. Lagouge M, Argmann C, Gerhart-Hines Z, et al. Resveratrol improves mitochondrial function and protects against metabolic disease by activating SIRT1 and PGC-1alpha. Cell. 2006;127(6):1109-1122.

31. Schmid B, Wimmer M, Tag C, Hoffmann R, Hofer HW. Protein phosphotyrosine phosphatases in Ascaris suum muscle. Mol Biochem Parasito. 1996;77(2):183-192.

32. Adachi M, Sekiya M, Arimura Y, et al. Protein-tyrosine phosphatase expression in pre-B cell NALM-6. Cancer Res. 1992;52(3):737-740.

33. Yi T, Cleveland JL, Ihle JN. Identification of novel protein tyrosine phosphatases of hematopoietic cells by polymerase chain reaction amplification. Blood. 1991;78(9):2222-2228.

34. Wang JF, Gong K, Wei DQ, Li YX, Chou KC. Molecular dynamics studies on the interactions of PTP1B with inhibitors: from the first phosphate-binding site to the second one. Prot Engineer Des Sel. 2009; 22(6):349-355.

35. Bakke J, Haj FG. Protein-tyrosine phosphatase 1B substrates and metabolic regulation. Semin Cell Dev Biol. 2015;37:58-65.
36. Picha KM, Patel SS, Mandiyan S, Koehn J, Wennogle LP. The role of the C-terminal domain of protein tyrosine phosphatase-1B in phosphatase activity and substrate binding. J Biol Chem. 2007;282(5): 2911-2917.

37. Gonzalez-Rodriguez A, Mas Gutierrez JA, Sanz-Gonzalez S, Ros M, Burks DJ, Valverde AM. Inhibition of PTP1B restores IRS1mediated hepatic insulin signaling in IRS2-deficient mice. Diabetes. 2010;59(3):588-599.

38. Zhang ZY, Lee SY. PTP1B inhibitors as potential therapeutics in the treatment of type 2 diabetes and obesity. Expert Opin Investig Drug. 2003;12(2):223-233.

39. Erbe DV, Wang S, Zhang YL, et al. Ertiprotafib improves glycemic control and lowers lipids via multiple mechanisms. Mol Pharmacol. 2005;67(1):69-77.

40. Kole HK, Garant MJ, Kole S, Bernier M. A peptide-based proteintyrosine phosphatase inhibitor specifically enhances insulin receptor function in intact cells. J Biol Chem. 1996;271(24):14302-14307.

41. Oliva RV, Bakris GL. Blood pressure effects of sodium-glucose cotransport 2 (SGLT2) inhibitors. J Am Soc Hyperten: JASH. 2014;8(5): 330-339.

42. Polidori D, Sha S, Mudaliar S, et al. Canagliflozin lowers postprandial glucose and insulin by delaying intestinal glucose absorption in addition to increasing urinary glucose excretion: results of a randomized, placebo-controlled study. Diabetes Care. 2013;36(8):2154-2161.

43. Fujimori Y, Katsuno K, Nakashima I, et al. Remogliflozin etabonate, in a novel category of selective low-affinity sodium glucose cotransporter (SGLT2) inhibitors, exhibits antidiabetic efficacy in rodent models. J Pharm Exp Ther. 2008;327(1):268-276.

44. Zambrowicz B, Freiman J, Brown PM, et al. LX4211, a dual SGLT1/ SGLT2 inhibitor, improved glycemic control in patients with type 2 diabetes in a randomized, placebo-controlled trial. Clin Pharmacol Ther. 2012;92(2):158-169.

45. Sands AT, Zambrowicz BP, Rosenstock J, et al. Sotagliflozin, a Dual SGLT1 and SGLT2 Inhibitor, as Adjunct Therapy to Insulin in Type 1 Diabetes. Diabetes Care. 2015;38(7):1181-1188.

46. Koepsell H. The Na+-D-glucose cotransporters SGLT1 and SGLT2 are targets for the treatment of diabetes and cancer. Pharmacol Ther. 2017;170:148-165.

47. Fiscaletti M, Lebel MJ, Alos N, Benoit G, Jantchou P. Two cases of mistaken polyuria and nephrocalcinosis in infants with glucose-galactose malabsorption: a possible role of 1,25(OH)2D3. Horm Res Paediatr. 2017.

48. Mather A, Pollock C. Glucose handling by the kidney. Kidney Int Suppl. 2011;(120):S1-S6.

49. DeFronzo RA. Insulin and renal sodium handling: clinical implications. Int J Obes. 1981;5(Suppl 1):93-104.

50. List JF, Whaley JM. Glucose dynamics and mechanistic implications of SGLT2 inhibitors in animals and humans. Kidney Int Suppl. 2011; (120):S20-S27.

51. Inzucchi SE, Bergenstal RM, Buse JB, et al. Management of hyperglycemia in type 2 diabetes: a patient-centered approach: position statement of the American Diabetes Association (ADA) and the European Association for the Study of Diabetes (EASD). Diabetes Care. 2012;35(6):1364-1379.

52. Wilding JP, Norwood P, T'Joen C, Bastien A, List JF, Fiedorek FT. A study of dapagliflozin in patients with type 2 diabetes receiving high doses of insulin plus insulin sensitizers: applicability of a novel insulin-independent treatment. Diab Care. 2009;32(9):1656-1662.

53. Kaku K, Inoue S, Matsuoka O, et al. Efficacy and safety of dapagliflozin as a monotherapy for type 2 diabetes mellitus in Japanese patients with inadequate glycaemic control: a phase II multicentre, randomized, double-blind, placebo-controlled trial. Diab Obes Metab. 2013; 15(5):432-440.

54. Ji L, Ma J, Li H, et al. Dapagliflozin as monotherapy in drug-naive Asian patients with type 2 diabetes mellitus: a randomized, blinded, prospective phase III study. Clin Ther. 2014;36(1):84-100.e9. 
55. Henry RR, Murray AV, Marmolejo MH, Hennicken D, Ptaszynska A, List JF. Dapagliflozin, metformin XR, or both: initial pharmacotherapy for type 2 diabetes, a randomised controlled trial. Int J Clin Pract. 2012; 66(5):446-456.

56. Kim GW, Chung SH. Clinical implication of SGLT2 inhibitors in type 2 diabetes. Arch Pharmacol Res. 2014;37(8):957-966.

57. Wang QM, Fiol CJ, DePaoli-Roach AA, Roach PJ. Glycogen synthase kinase- 3 beta is a dual specificity kinase differentially regulated by tyrosine and serine/threonine phosphorylation. J Biol Chem. 1994; 269(20):14566-14574.

58. Woodgett JR, Cohen P. Multisite phosphorylation of glycogen synthase. Molecular basis for the substrate specificity of glycogen synthase kinase-3 and casein kinase-II (glycogen synthase kinase-5). Biochim Biophys Acta. 1984;788(3):339-347.

59. Doble BW, Woodgett JR. GSK-3: tricks of the trade for a multi-tasking kinase. J Cell Sci. 2003;116(Pt 7):1175-1186.

60. Xie H, Wen H, Zhang D, et al. Designing of dual inhibitors for GSK3 beta and CDK5: virtual screening and in vitro biological activities study. Oncotarget. 2017;8(11):18118-18128.

61. Dudek H, Datta SR, Franke TF, et al. Regulation of neuronal survival by the serine-threonine protein kinase Akt. Science. 1997; 275(5300):661-665.

62. Ravingerova T, Matejikova J, Neckar J, Andelova E, Kolar F. Differential role of PI3K/Akt pathway in the infarct size limitation and antiarrhythmic protection in the rat heart. Mol cell Biochem. 2007; 297(1-2):111-120.

63. Yin D, Woodruff M, Zhang Y, et al. Morphine promotes Jurkat cell apoptosis through pro-apoptotic FADD/P53 and anti-apoptotic PI3K/Akt/NF-kappaB pathways. J Neuroimmunol. 2006;174(1-2): 101-107.

64. Crouthamel MC, Kahana JA, Korenchuk S, et al. Mechanism and management of AKT inhibitor-induced hyperglycemia. Clin Cancer Res. 2009; 15(1):217-225.
65. Mussmann R, Geese M, Harder F, et al. Inhibition of GSK3 promotes replication and survival of pancreatic beta cells. J Biol Chem. 2007; 282(16):12030-12037.

66. World Health Organization. Investing to Overcome the Global Impact of Neglected Tropical Diseases: Third WHO Report on Neglected Tropical Diseases. World Health Organization; 2015. Available from: http://apps. who.int/iris/bitstream/10665/152781/1/9789241564861_eng.pdf?ua=1 Accessed January 28, 2017.

67. Hedrington MS, Davis SN. Discontinued in 2013: diabetic drugs. Expert Opin Investig Drugs. 2014;23(12):1703-1711.

68. Colca JR. Discontinued drug therapies to treat diabetes in 2014. Expert Opin Investig Drugs. 2015;24(9):1241-1245.

69. Kim NH, Yu T, Lee DH. The nonglycemic actions of dipeptidyl peptidase-4 inhibitors. BioMed Res Int. 2014;2014:368703.

70. Abel T, Feher J. [A new therapeutic possibility for type 2 diabetes: DPP-4 inhibitors (sitagliptin)]. Orv Hetil. 2010;151(25):1012-1016. Hungarian.

71. Doyle ME, Egan JM. Mechanisms of action of glucagon-like peptide 1 in the pancreas. Pharmacol Ther. 2007;113(3):546-593.

72. Vitku J, Starka L, Bicikova M, et al. Endocrine disruptors and other inhibitors of 11ß-hydroxysteroid dehydrogenase 1 and 2: tissue-specific consequences of enzyme inhibition. J Ster Biochem Mol Biol. 2016; 155(Pt B):207-216.

73. Marx N, Schönbeck U, Lazar MA, Libby P, Plutzky J. Peroxisome proliferator-activated receptor gamma activators inhibit gene expression and migration in human vascular smooth muscle cells. Circ Res. 1998;83(11):1097-1103.

74. Mayer-Barber KD, Sher A. Cytokine and lipid mediator networks in tuberculosis. Immunol Rev. 2015;264(1):264-275.

75. Colca JR. Discontinued drugs in 2012: endocrine and metabolic. Expert Opin Investig Drugs. 2013;22(10):1305-1313.

76. Graham DJ, Green L, Senior JR, Nourjah P. Troglitazone-induced liver failure: a case study. Am J Med. 2003;114(4):299-306.
Drug Design, Development and Therapy

\section{Publish your work in this journal}

Drug Design, Development and Therapy is an international, peerreviewed open-access journal that spans the spectrum of drug design and development through to clinical applications. Clinical outcomes, patient safety, and programs for the development and effective, safe, and sustained use of medicines are the features of the journal, which

\section{Dovepress}

has also been accepted for indexing on PubMed Central. The manuscript management system is completely online and includes a very quick and fair peer-review system, which is all easy to use. Visit http://www.dovepress.com/testimonials.php to read real quotes from published authors.

Submit your manuscript here: http://www.dovepress.com/drug-design-development-and-therapy-journal 